\title{
THE ROLE OF BETA-1 RECEPTOR GENE POLYMORPHISM IN BETA-BLOCKER THERAPY FOR VASOVAGAL SYNCOPE
}

\author{
Adem Atici ${ }^{*}$, Mehmet Rasih-Sonsoz ${ }^{2}$, Hasan Ali-Barman ${ }^{3}$, Eser Durmaz ${ }^{4}$, Ahmet Demirkiran ${ }^{2}$,

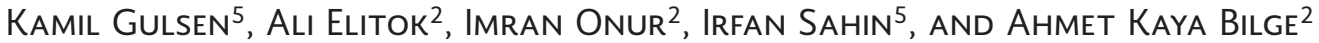 \\ Cardiology Departments of ${ }^{1}$ Istanbul Medeniyet University, Goztepe Training and Research Hospital, Istanbul; \\ ${ }^{2}$ Istanbul School of Medicine, Istanbul University, Istanbul; ${ }^{3}$ Okmeydani Training and Research Hospital, Istanbul; \\ ${ }^{4}$ Cerrahpasa School of Medicine, Istanbul University, Istanbul, and ${ }^{5}$ Bagcilar Training and Research Hospital, \\ Istanbul, Turkey
}

\begin{abstract}
Background: Vasovagal syncope (VVS) is a common clinical condition involving genetic background. The role of beta-blockers in the treatment is controversial. Objective: The aim of this study was to investigate the effect of beta- 1 gene polymorphism on beta-blocker therapy in patients with VVS. Methods: We included 123 patients who were diagnosed with VVS after the tilttable test. We searched for the polymorphism Arg389Gly (rs1801253) in the beta-1 adrenoceptor gene. Results: Overall, 64 patients (52\%) had Arg389Arg genotype and 59 patients (48\%) had Arg389Gly genotype. The syncopal episodes of patients with Arg389Arg genotype were more frequent compared with patients having Arg389Gly genotype (total syncopal episodes [TSE], $7.9 \pm 3.7$ vs. $6.4 \pm 3.0 ; p=0.012$ ). TSE in patients with Arg389Arg genotype decreased significantly after 18 months of beta-blocker treatment ( $7.9 \pm 3.7$ vs. $3.0 \pm 1.4, p<0.001)$. After 18 months of beta-blocker treatment, patients with Arg389Arg genotype had significantly fewer syncopal episodes than patients with Arg389Gly genotype (3.0 \pm 1.4 vs. $6.8 \pm 3.2$, $p<0.001$ ). Conclusions: Results of beta-blocker therapy in patients with Arg389Arg genotype suggest that VVS pathophysiology is a multifactorial condition, with genetic, psychological, and environmental components, and therefore, treatment selection can be based on gene polymorphism. (REV INVEST CLIN. 2020;72(5):300-7)
\end{abstract}

Key words: Genetic polymorphism. Vasovagal syncope. Beta-blocker treatment.

\section{INTRODUCTION}

Syncope is a frequent symptom in the general population and is characterized by sudden-onset unconsciousness and absence of postural tonus ${ }^{1}$. In the general population, $40 \%$ of people have experienced at least one episode of syncope ${ }^{2}$. Although syncope is considered to have a benign prognosis, it is sometimes associated with mortal clinical conditions ${ }^{3}$. The most common cause of syncope is vasovagal syncope $(\mathrm{VVS})^{4}$. Although the underlying pathophysiologic mechanism of VVS is unclear, it is believed that abnormal and excessive mechanoreceptor response, which causes hypotonia or bradycardia, is the primary
*Corresponding author:

Adem Atici

E-mail: adematici10@gmail.com
Received for publication: 23-11-2019

Approved for publication: 10-03-2020

DOI: $10.24875 / R I C .20003319$

0034-8376 / (C) 2020 Revista de Investigación Clínica. Published by Permanyer. This is an open access article under the CC BY-NC-ND license (http://creativecommons.org/licenses/by-nc-nd/4.0/). 
etiology of VVS. Increased autonomous nervous system activity before the syncopal episode may be due to altered function or structure of the cardiac adrenergic receptor $(A R)^{5}$. Several gene polymorphisms that affect the function or structure of cardiac AR have been described recently. Notably, the Arg389Gly beta-1 adrenoreceptor gene polymorphism has been shown to cause syncope through AR dysfunction ${ }^{6,7}$. Furthermore, beta-1 receptor gene polymorphism affects the response to beta-blocker therapy in patients with coronary artery disease, hypertension, and heart failure ${ }^{8-12}$.

Beta-blockers were the most commonly prescribed therapy in VVS previously. Beta-blockers are thought to suppress peripheral vasodilatation and inhibit ventricular mechanoreceptors. Although recent clinical trials have failed to demonstrate the benefits of betablocker therapy over placebo ${ }^{13,14}$, these trials did not consider beta- 1 gene polymorphisms. This study aimed to investigate beta- 1 gene polymorphisms in patients with VVS and assess the favorable effects on the prognosis with beta-blocker therapy selection based on gene polymorphisms.

\section{METHODS}

We included 123 patients who were admitted to our outpatient clinic between 2014 and 2017 with the complaint of at least three episodes of syncope in a year and who were diagnosed with VVS after the tilttable test. All patients were followed up at a specialized arrhythmia outpatient clinic staffed with an expert team comprising one academician and one cardiology resident. Patients with structural heart disease, sick sinus syndrome, orthostatic hypotension, atrial fibrillation, metabolic or neurological syncope, or on any prescription medicines were excluded from the study. All participants gave their written informed consent for the study, which was approved by the Institutional Ethical Committee, per the Declaration of Helsinki.

Syncope is defined as the sudden, temporary, and complete loss of consciousness accompanied by the inability to sustain postural tonus that is associated with quick and spontaneous recovery. When none of the underlying etiologies of syncope is present, such as cardiac, reflex, neurologic, or metabolic effects, it is defined as pseudosyncope ${ }^{15}$.
Demographics, clinical characteristics, and 12-lead electrocardiogram findings of the participants were recorded. The standard evaluation included M-mode, two-dimensional, and Doppler studies according to the recommendations of the American Society of Echocardiography. Transthoracic echocardiography was carried out using a Philips iE33 echocardiography machine and X5 transducer (Philips Healthcare, Andover, Massachusetts, USA) with the patient in the left lateral decubitus position. Beta-blocker treatment was started using the lowest dose (metoprolol succinate $25 \mathrm{mg}$ ) and titrated up to the maximum dose until the patient tolerated the dose $(200 \mathrm{mg}$ for metoprolol succinate). Dose titration was made 3-5 days after the changes. Overall, 34 patients were excluded due to intolerance to the beta-blocker treatment. The number of syncopes 18 months before the diagnosis was recorded. Patients were followed up at $1,3,6,12$, and 18 months after treatment and were asked regarding treatment compliance, the occurrence of syncope, or any other symptom. The primary outcome was recurrent syncopal episodes. Presyncope was not considered as a treatment failure. Additional visits were scheduled to evaluate patients' clinical status, if necessary. The patients and treating physicians were fully blinded to the genotype.

\section{Head-up tilt (HUT) protocol}

A HUT test was performed using an electrically controlled tilt-table with a footboard for weight-bearing. Blood pressure, heart rate (HR), heart rhythm, and right forearm blood flow were closely monitored and recorded. Blood pressure was automatically assessed every $1 \mathrm{~min}$. The test was performed after the initial observation of $15 \mathrm{~min}$ with the patient in the supine position. Patients were tilted at $70^{\circ}$ for up to $45 \mathrm{~min}$ without drug provocation ${ }^{16,17}$. If a presyncope with hypotension occurred during the test, the tilt table was rapidly lowered to return the patient to the supine position, and the study was terminated.

Test results were categorized as vasodepressor type in patients who had hypotension, syncope, or presyncope; cardioinhibitory type if bradyarrhythmia occurred; and mixed type when both hypotension and bradyarrhythmia occurred. Bradycardia was defined as a $20 \%$ decrease from the baseline HR or a decrease of more than 20 beats in a minute. Hypotension was defined as a decrease in systolic blood 
pressure (SBP) to more than $20 \%$ of baseline or more than $30 \mathrm{mmHg}$ decrease of maximum systolic pressure.

\section{Sample collection and biochemical analysis}

Blood samples were collected from patients enrolled in the study, as well as healthy volunteers. A 400- $\mu$ l sample of uncoagulated blood was placed in a $1.5-\mathrm{ml}$ centrifuge tube and $800 \mu \mathrm{l}$ of LB buffer was added. The sample was centrifuged at $6000 \mathrm{rpm}$ for $3 \mathrm{~min}$ and the supernatant was removed. In addition, the LB buffer step was repeated when a larger sample of DNA was required. The remaining pellet was white or slightly pink. The pellet was vortexed until a homogeneous appearance was obtained.

Approximately $20 \mu \mathrm{l}$ protein-C and $220 \mu \mathrm{l}$ BB buffer were then added to the sample and incubated for 10 $15 \mathrm{~min}$ at $65^{\circ} \mathrm{C}$. After incubation, $220 \mu \mathrm{l}$ of ethanol was added. The mixture was transferred to filtered tubes and centrifuged for $2 \mathrm{~min}$ at $12,000 \mathrm{rpm}$. The liquid and the filtered portion of the centrifuged mixture were poured and $500 \mu \mathrm{l}$ of wash solution was poured over a filter. The filter was centrifuged without any reactive material at $12,000 \mathrm{rpm}$ for $3 \mathrm{~min}$. The filter was placed in a new microfuge tube, $30-100 \mu \mathrm{l}$ elution buffer was added, and the sample was incubated at room temperature for 4-5 $\mathrm{min}$ at room temperature and centrifuged for $2 \mathrm{~min}$ at $12,000 \mathrm{rpm}$. The filter was then displaced and the microfuge tube now contained the DNA that was measured using a NanoDrop. Samples with concentrations higher than $50 \mathrm{ng} / \mu \mathrm{l}$ and between 1.8 and 2.0 OD were stored at $-20^{\circ} \mathrm{C}$. The above protocol was repeated for samples that did not meet these requirements.

\section{Analysis of Arg389Gly polymorphisms}

In this study, we used the amplification refractory mutation system technique to determine polymorphic alleles using real-time polymerase chain reaction. We used this technique because it is reliable, easy to assess, and produces quality results. This technique depends on the DNA polymerase enzyme that starts reactions according to the last nucleotide coupling. The reaction uses specific primers designed to integrate with mutated primers that contain an altered nucleotide. The reactions were prepared in two distinct tubes with primers designed with appropriate nucleotides to integrate with the polymorphic alleles. Control primers were used to check the occurrence of the reaction. Alleles located on the DNA were determined based on the reaction product. If the reaction occurred in one tube, the allele was defined as homozygous and called heterozygous if the reaction occurred in both tubes.

In this study, we screened for the Arg389Gly polymorphism (rs1801253) in the beta-1 adrenoceptor gene (ADRB1). The $\mathrm{C}$ allele encoded the amino acid arginine and the $G$ allele encoded glycine. Thus, the CC genotype was replaced with Arg/Arg, the GG genotype was replaced with Gly/Gly, and the CG genotype was replaced with Arg/Gly.

\section{Statistical analysis}

Hardy-Weinberg equilibrium (HWE) was computed for the expected genotype distribution. The HWE was tested by using FINETTI Program (http://ihg. gsf.de/cgi-bin/hw/hwa2.pl). Data were analyzed using SPSS software (version 18, SPSS Inc., Chicago, IL, USA). Data were presented as the mean \pm standard deviation for quantitative variables and as number (valid percent) for categorical variables. The distribution of continuous variables was evaluated using the Kolmogorov-Smirnov or Shapiro-Wilk tests. A Chi-square test was used to assess the intergroup differences in categorical variables. Normally distributed data of independent groups were compared using the independent samples t-test. The MannWhitney $U$ test was used for comparison of non-normally distributed data. Paired t-tests were used to evaluate quantitative data before and after the treatment. $p<0.05$ was considered statistically significant.

\section{RESULTS}

Of the 123 patients diagnosed with VVS, 64 (52\%) had the Arg389Arg genotype and 59 (48\%) had the Arg389Gly genotype. No Gly/Gly genotype was noted among the patients with VVS. No differences related to age or sex were identified between the Arg389Arg genotype and Arg389Gly genotype groups. The average age of the Arg389Arg genotype group was 24.9 years, and that of the Arg389Gly genotype 
Table 1. Baseline characteristics of patients with Arg389Arg and Arg389Gly polymorphisms

\begin{tabular}{lccc}
\hline $\begin{array}{l}\text { Gene polymorphism } \\
(\mathrm{n}=123)\end{array}$ & Arg389Arg (64) & Arg389Gly (59) & $\mathrm{p}$ \\
\hline Age, years & $24.9 \pm 4.2$ & $25.6 \pm 4.4$ & 0.392 \\
Female sex (n, \%) & $40(67)$ & $40(62)$ & 0.538 \\
Left ventricular ejection fraction (\%) & $66.1 \pm 4.9$ & $67.2 \pm 4.1$ & 0.176 \\
Systolic blood pressure (mmHg) & $120.5 \pm 7.0$ & $116.5 \pm 9.7$ & 0.011 \\
Diastolic blood pressure (mmHg) & $74.1 \pm 7.1$ & $72.4 \pm 8.5$ & 0.237 \\
Heart rate (beats per minute) & $81.3 \pm 5.2$ & $74.3 \pm 5.2$ & $<0.001$ \\
Total syncope episodes & $7.9 \pm 3.7$ & $6.4 \pm 3.0$ & 0.012 \\
Beta-blocker dose (mg) & $108.2 \pm 46.0$ & $101.6 \pm 43.7$ & 0.424 \\
(after diagnosis) & & & \\
\hline
\end{tabular}

group was 25.6 years. Intergroup comparison revealed no statistically significant differences related to left ventricular ejection fraction (66.1 \pm 4.9 vs. 67.2 $\pm 4.1, \mathrm{p}=0.176$ ). Compared with Arg389Gly genotype group, the baseline SBP and HR of the Arg389Arg genotype group were higher (SBP: $120.5 \pm 7.0$ vs. $116.5 \pm 9.7, p=0.011$; HR: $81.3 \pm 5.2$ vs. $74.3 \pm 5.2$, $\mathrm{p}<0.001)$. The pretreatment syncopal episodes in patients with Arg389Arg genotype were more frequent compared with those with Arg389Gly genotype (total syncopal episodes [TSE]: $7.9 \pm 3.7$ vs. $6.4 \pm 3.0$; $\mathrm{p}=0.012$ ). Intergroup comparison revealed no statistically significant differences related to beta-blocker dose (108.2 \pm 46.0 vs. $101.6 \pm$ 43.7, $\mathrm{p}=0.493$ ). Table 1 demonstrates the baseline characteristics of patients with Arg389Arg genotype and Arg389Gly genotype.

SBP, diastolic blood pressure (DBP), and HR before treatment and after 1 month of treatment were compared in patients with both groups. SBP, DBP, and HR after treatment was statistically lower in both groups, and more marked in patients with the Arg389Arg genotype $(120.5 \pm 7.0$ vs. $115.7 \pm 6.7$, $p<0.001$; $74.1 \pm 7.1$ vs. $71.7 \pm 8.7, p=0.030 ; 81.3 \pm 5.2$ vs. $78.4 \pm 3.5, p<0.001$ ). The SBP, DBP, and HR in Arg$389 \mathrm{Gly}$ genotype group before and after 1 month of treatment were as follows: $116.5 \pm 9.7$ vs. $112.9 \pm$ 7.9, $\mathrm{p}=0.025 ; 72.4 \pm 8.5$ vs. $70.3 \pm 10, \mathrm{p}=0.044$; and $74.3 \pm 5.2$ vs. $72.6 \pm 4.5, p=0.026$, respectively. At 3, 6, 12, and 18 months after treatment, SBP, DBP, and HR were not statistically different when compared with the values obtained at 1 month.
The TSE of patients before and after 18 months of diagnosis was compared individually in the groups. The number of TSE in patients with Arg389Arg genotype decreased significantly after beta-blocker treatment ( $7.9 \pm 3.7$ vs. $3.0 \pm 1.4, \mathrm{p}<0.001)$. However, no significant change was noted in patients with Arg389 Gly genotype $(6.4 \pm 3.0$ vs. $6.8 \pm 3.2, p=0.107)$ (Fig. 1).

A further intergroup comparison was performed regarding TSE after beta-blocker treatment. After 18 months of beta-blocker treatment, patients with the Arg389Arg genotype had significantly fewer episodes than patients with the Arg389Gly genotype (3.0 \pm 1.4 vs. $6.8 \pm 3.2, p<0.001$ ) (Fig. 2 ).

The HWE distribution was detected using control groups in two similar studies conducted in our population since there was no control group in our study. Genotype frequencies of ADRB1 gene Arg389 Gly polymorphism of 205 patients in two studies were evaluated. HWE balance was examined and genotype frequencies do not match HWE distribution. However, this polymorphism showed significant deviation from HWE ( $<$ 0.05) in the study group (Table 2 and Supplemental Table 1).

\section{DISCUSSION}

In this study, we investigated the effect of beta-1 gene polymorphism on beta-blocker therapy in patients with VVS. Our principal findings were as follows: 
Figure 1. Box-and-whisker plot comparing syncope numbers of patients with Arg389Arg (Group 1) and Arg389Gly (Group 2) polymorphisms 18 months before (blue boxes) and 18 months after (red boxes) treatment. Numbers above bars are means \pm S.D.

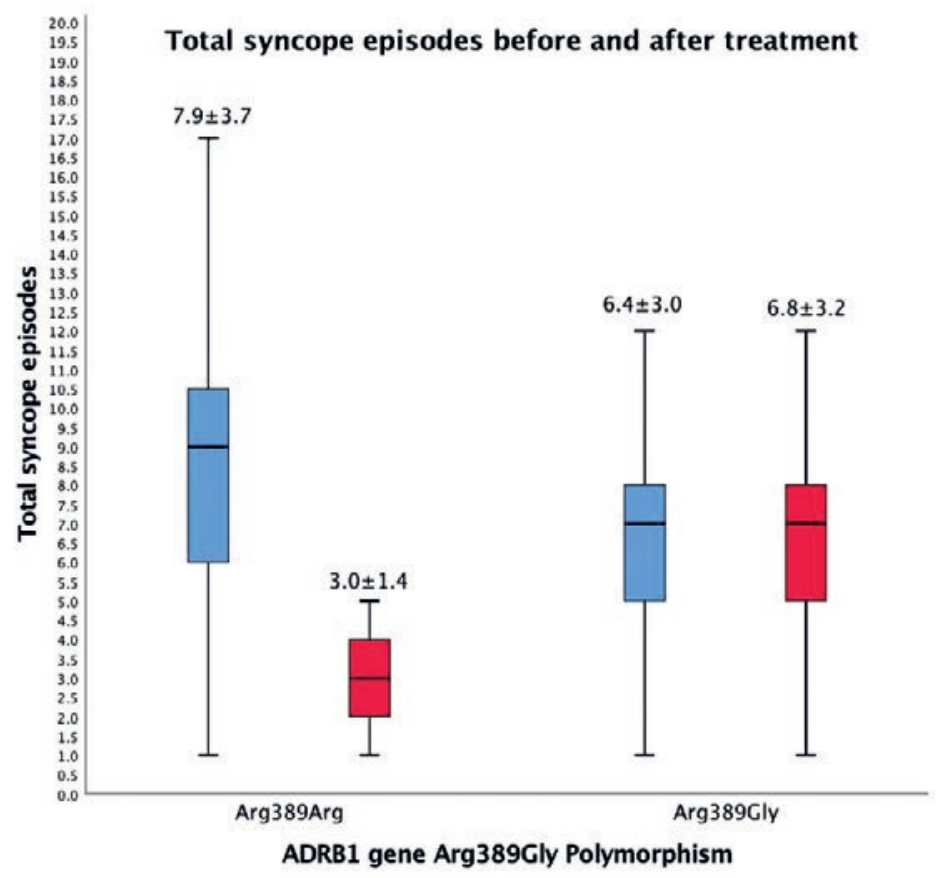

18 months before treatment

18 months after treatment

Figure 2. Box-and-whisker plot showing the frequency of syncope according to gene polymorphism in patients with vasovagal syncope diagnosis post-treatment. Numbers above bars are means \pm S.D.

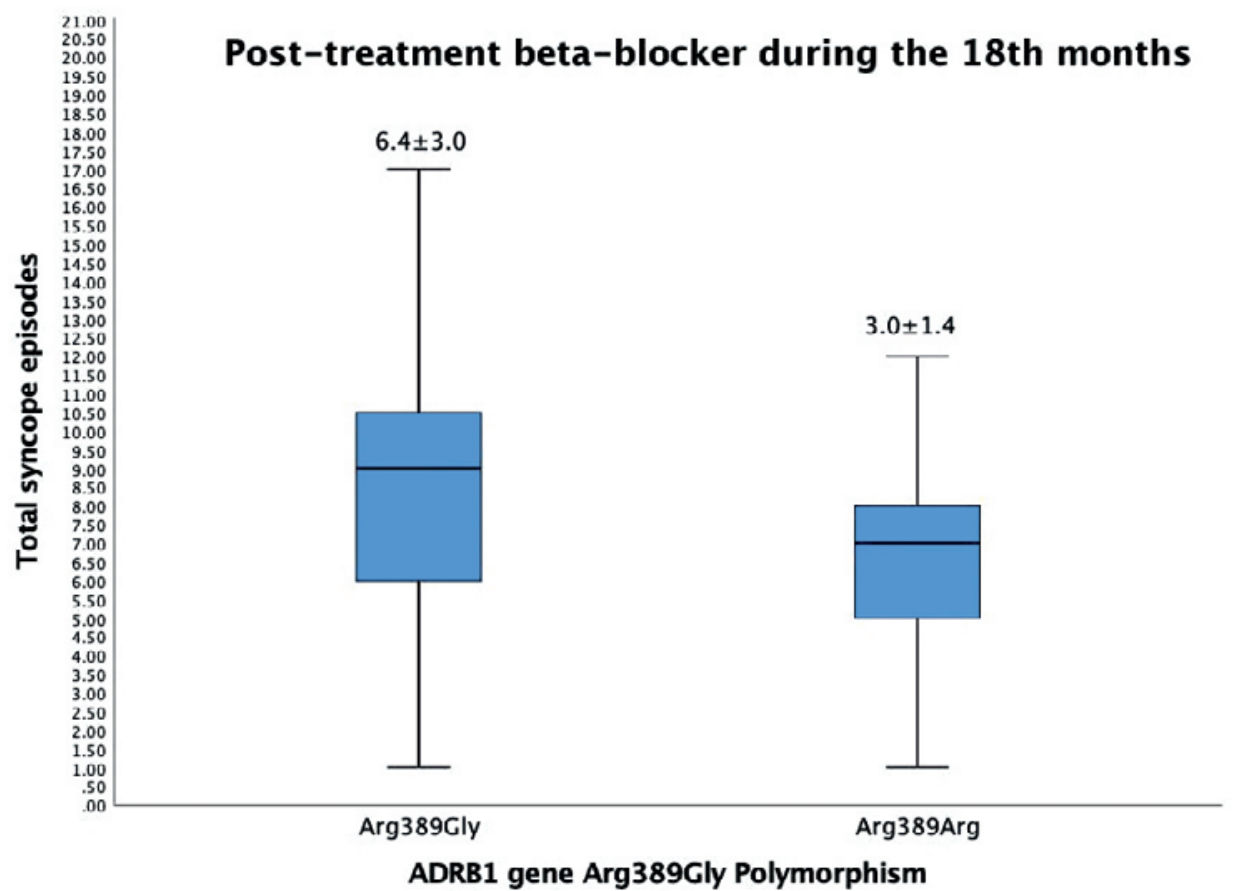


Table 2. Genotype of the control group of two studies and genotype of our patients

\begin{tabular}{lccc}
\hline Genotypes of control groups & $(\mathrm{n}=\mathbf{2 0 5})$ & Genotype frequencies (\%) & Arg allele frequency \\
\hline Arg/Arg & 7 & $3(41)$ & 0.356 \\
Arg/Gly & 132 & $64(39)$ & Gly allele frequency \\
Gly/Gly & 66 & $32(19)$ & 0.644 \\
Genotypes of our patients & $(\mathrm{n}=123)$ & Genotype frequencies (\%) & Arg allele frequency \\
Arg/Arg & 64 & $52(03)$ & 0.760 \\
Arg/Gly & 59 & $47(97)$ & 0 \\
Gly/Gly & 0 & 0 & 0.240 \\
\hline
\end{tabular}

i. The SBP and HR in patients with Arg389Arg genotype were significantly higher than in patients with Arg389Gly genotype

ii. TSE in patients with Arg389Arg genotype was significantly higher than in patients with Arg389Gly genotype before treatment

iii. After treatment, TSE in patients with Arg389Arg genotype was significantly lower than before treatment

iv. No significant differences were noted regarding TSE in patients with Arg389Gly genotype after treatment

v. After the treatment, the TSE in patients with Arg389Arg genotype was significantly lower compared with patients having Arg389Gly genotype.

VVS is the most frequent type of syncope and requires a multidisciplinary treatment approach4. Conventional treatment of VVS, which includes both pharmacological and non-pharmacological treatments, is often insufficient. In general, beta-blockers are prescribed initially as the pharmacological treatment of VVS based on results of animal studies18. Adrenergic stimulation, which eventually activates cardiac mechanoreceptors and increases epinephrine levels during syncopal episodes ${ }^{19,20}$, led to the thought that betablocker therapy could be beneficial21,22. It was hypothesized that beta-blockers could prevent cardiac mechanoreceptor activation by exerting negative inotropic effects and blocking peripheral effects of betareceptor stimulation ${ }^{21}$.

Beta-1 AR is highly expressed in the cardiac myocyte plasma membrane. Stimulation of this receptor results in chronotropic, inotropic, and dromotropic effects through G-protein associated signal activation $^{23}$. Human ADRB1 encodes a functional protein with 477 amino acids through at least nine different nucleotide sequences ${ }^{24,25}$. Two major gene loci have been described that may alter the function of this protein. Notably, per the nucleotide variant \#145, the amino acid at position 49 encodes a serine or glycine (Ser49Gly), and per the nucleotide variant \#1165, the amino acid at position 389 encodes an arginine or glycine (Arg389Gly). The Arg389 variant is more potent than Gly389 concerning adenylyl cyclase stimulation ${ }^{26}$ and causes 3-4 times more signal transition capacity. The Arg389 variant demonstrates more potent inotropic effects on human heart preparations ${ }^{27}$. Among family members with different alleles, members with the Arg389 allele have shown a higher HR than members with the Gly389 allele. Furthermore, the increase in contractility and fractional shortening following dobutamine infusion is markedly higher in members with the Arg389 allele compared with those having Gly3896,28,29. In the present study, SBP and HR of patients with the Arg389Arg genotype were higher than those with Arg389 Gly genotype (SBP: $120.5 \pm 7.0$ vs.116.5 \pm 9.7 , $p=0.011$; HR: $81.3 \pm 5.2$ vs. $74.3 \pm 5.2, p<0.001$ ). In addition, it has been demonstrated that cells transfected with Arg389 and human ventricular myocardial cell membrane have more affinity for agonist agents, such as norepinephrine, compared with Gly38926. Similarly, patients with the Arg389 genotype exhibited markedly decreased HR, blood pressure, and plasma renin activity after beta-blocker therapy compared with patients having the Gly389 genotype ${ }^{24}$. Likewise, our study observed that SBP, $\mathrm{DBP}$, and HR were statistically lower in both groups after treatment, and more marked in patients with 
the Arg389Arg genotype (the before and after 1 month of treatment values for SBP, DBP, and HR were $116.5 \pm 9.7$ vs. $112.9 \pm 7.9, p=0.025 ; 72.4$ \pm 8.5 vs. $70.3 \pm 10, p=0.044$; and $74.3 \pm 5.2$ vs. $72.6 \pm 4.5, p=0.026$, respectively). Our study findings revealed that patients with Arg389Arg genotype have an excellent response to beta-blocker therapy due to the higher inotropic, chronotropic, and dromotropic effects.

Most studies that investigated the efficacy of betablocker treatment in patients with VVS have revealed conflicting results. Previous studies had demonstrated the beneficial effects of beta-blocker therapy $21,30,31$, whereas recent studies have failed to demonstrate any such benefits ${ }^{14,32,33}$, especially the randomized trials. However, no studies have investigated the effect of beta- 1 adrenoceptor polymorphism on beta-blocker therapy response. Nevertheless, recent clinical trials have advocated that beta- 1 adrenoceptor polymorphism results in signal activation of the receptors and alters the treatment response to beta-blocker therapy ${ }^{5,34}$. Such variations have also been demonstrated in patients with coronary artery disease, such as in patients with ADRB1 gene polymorphism, who exhibit a different treatment response to beta-blocker therapy ${ }^{35,36}$. Moreover, in patients with heart failure, it has been demonstrated that beta- 1 adrenoceptor polymorphism alters the treatment response to beta-blocker therapy. Similarly, mice with the Arg389 gene polymorphism showed an excellent treatment response to beta-blocker therapy ${ }^{37}$, probably because beta-blockers inhibit beta- 1 adrenoceptor function relatively more. In the present study, patients with VVS treated with beta-blocker therapy were compared regarding the number of syncopal and presyncopal episodes. During the 18-month follow-up after treatment, patients with the Arg389Arg genotype experienced significantly fewer syncope episodes compared with patients with the Arg389Gly genotype.

A primary limitation of our study is that it was a single-center study and that there was no control group. Since there was no control group in our study, the HWE distribution was determined using the control groups in two similar studies previously conducted in the Turkish population ${ }^{38,39}$. Furthermore, the relatively short follow-up period, the absence of repeat tilt-table test to verify treatment efficacy, and the lack of patients with Gly/Gly genotype are the other limitations.

In conclusion, when treating patients with VVS, the significance of genetics should be considered, besides the environmental and physiological factors. This theory is aptly supported by our study findings, which demonstrated that VVS is more frequent in patients with Arg389Arg genotype. Furthermore, our results also indicated that ADRB1 gene polymorphism plays a crucial role in response to beta-blocker therapy.

\section{ACKNOWLEDGMENTS}

We would like to thank Istanbul University Scientific Research Project for its support.

\section{SUPPLEMENTARY DATA}

Supplementary data are available at Revista de Investigación Clínica online (www.clinicalandtranslationalinvestigation.com). These data are provided by the corresponding author and published online for the benefit of the reader. The contents of supplementary data are the sole responsibility of the authors.

\section{REFERENCES}

1. Vaddadi G, Lambert E, Corcoran SJ, Esler MD . Postural syncope: mechanisms and management. Med J Aust. 2007; 187:299-304.

2. Brignole $M$, Alboni $P$, Benditt $D$, Bergfeldt L, Blanc JJ, Bloch Thomsen PE, et al. Guidelines on management (diagnosis and treatment) of syncope. Eur Heart J. 2001;22:1256-306.

3. Rose MS, Koshman ML, Spreng S, Sheldon R. The relationship between health-related quality of life and frequency of spells in patients with syncope. J Clin Epidemiol. 2000;53:1209-16.

4. Ganzeboom KS, Mairuhu G, Reitsma JB, Linzer M, Wieling W, van Dijk N. Lifetime cumulative incidence of syncope in the general population: a study of 549 Dutch subjects aged 35-60 years. J Cardiovasc Electrophysiol. 2006;17:1172-6.

5. Small KM, McGraw DW, Liggett SB. Pharmacology and physiology of human adrenergic receptor polymorphisms. Annu Rev Pharmacol Toxicol. 2003;43:381-411.

6. Hernández-Pacheco G, González-Hermosillo A, Murata C, Yescas P, Espínola-Zavaleta N, Martínez M, et al. Arg347Cys polymorphism of $\alpha 1$ a-adrenergic receptor in vasovagal syncope. Case-control study in a Mexican population. Auton Neurosci. 2014;183:66-71.

7. Márquez MF, Fragoso JM, Pérez-Pérez D, Cázares-Campos I, Totomoch-Serra A, Gómez-Flores JR, et al. Polymorphisms in $\beta$-adrenergic receptors are associated with increased risk to have a positive head-up tilt table test in patients with vasovagal syncope. Rev Invest Clin. 2019;71:124-32.

8. Bunova SS, Zamakhina OV, Usacheva EV, Nelidova AV, Voronina EN. Effect of bisoprolol on heart rate variability in patients with 
coronary atherosclerosis: dependence on polymorphisms of -1 adrenergic receptor gene. Kardiologiia. 2017;57:20-4.

9. Liu WN, Fu KL, Gao HY, Shang YY, Wang ZH, Jiang GH, et al. $\beta 1$ adrenergic receptor polymorphisms and heart failure: a metaanalysis on susceptibility, response to $\beta$-blocker therapy and prognosis. PLoS One. 2012;7:e37659.

10. Lee HY, Chung WJ, Jeon HK, Seo HS, Choi DJ, Jeon ES, et al. Impact of the $\beta-1$ adrenergic receptor polymorphism on tolerability and efficacy of bisoprolol therapy in Korean heart failure patients: association between $\beta$ adrenergic receptor polymorphism and bisoprolol therapy in heart failure (ABBA) study. Korean J Intern Med. 2016;31:277-87

11. Wu D, Li G, Deng M, Song W, Huang X, Guo X, et al. Associations between ADRB1 and CYP2D6 gene polymorphisms and the response to $\beta$-blocker therapy in hypertension. J Int Med Res. 2015;43:424-34.

12. Leineweber K, Bogedain P, Wolf C, Wagner S, Weber M, Jakob $\mathrm{HG}$, et al. In patients chronically treated with metoprolol, the demand of inotropic catecholamine support after coronary artery bypass grafting is determined by the Arg389Gly-beta 1-adrenoceptor polymorphism. Naunyn Schmiedebergs Arch Pharmacol. 2007;375:303-9.

13. Brignole M, Moya A, de Lange FJ, Deharo JC, Elliott PM, Fanciulli A, et al. 2018 ESC Guidelines for the diagnosis and management of syncope. Eur Heart J. 2018;39:1883-948.

14. Sheldon R, Connolly S, Rose S, Klingenheben T, Krahn A, Morillo $C$, et al. Prevention of Syncope Trial (POST): a randomized, placebo-controlled study of metoprolol in the prevention of vasovagal syncope. Circulation. 2006;113:1164-70.

15. Shen WK, Sheldon RS, Benditt DG, Cohen MI, Forman DE, Goldberger ZD, et al. 2017 ACC/AHA/HRS guideline for the evaluation and management of patients with syncope: executive summary: a report of the american college of cardiology/American heart association task force on clinical practice guidelines and the heart rhythm society. Circulation. 2017:136:e25-e59.

16. Kapoor WN. Using a tilt table to evaluate syncope. Am J Med Sci. 1999;317:110-6

17. Benditt DG, Remole S, Bailin S, Dunnigan A, Asso A, Milstein S. Tilt table testing for evaluation of neurally-mediated (cardioneurogenic) syncope: rationale and proposed protocols. Pacing Clin Electrophysiol. 1991;14:1528-37

18. Sra JS, Murthy VS, Jazayeri MR, Shen YH, Troup PJ, Avitall B, et al. Use of intravenous esmolol to predict efficacy of oral betaadrenergic blocker therapy in patients with neurocardiogenic syncope. J Am Coll Cardiol. 1992;19:402-8.

19. Sra JS, Murthy V, Natale A, Jazayeri MR, Dhala A, Deshpande S, et al. Circulatory and catecholamine changes during head-up tilt testing in neurocardiogenic (vasovagal) syncope. Am J Cardiol. 1994:73:33-7.

20. Calkins H, Seifert M, Morady F. Clinical presentation and longterm follow-up of athletes with exercise-induced vasodepressor syncope. Am Heart J. 1995;129:1159-64.

21. Lippman N, Stein KM, Lerman BB. Differential therapeutic responses of patients with isoproterenol-dependent and isoproterenol-independent vasodepressor syncope. Am Heart J. 1994; 128:1110-6.

22. Biffi M, Boriani G, Sabbatani P, Bronzetti G, Frabetti L, Zannoli $\mathrm{R}$, et al. Malignant vasovagal syncope: a randomised trial of metoprolol and clonidine. Heart. 1997;77:268-72.

23. Mendez R, Kabela E. Cardiac pharmacology. Annu Rev Pharmacol. 1970;10:291-312.
24. Ahles A, Engelhardt S. Polymorphic variants of adrenoceptors: pharmacology, physiology, and role in disease. Pharmacol Rev. 2014;66:598-637

25. Dorn GW 2nd. Adrenergic signaling polymorphisms and their impact on cardiovascular disease. Physiol Rev. 2010;90: 1013-62.

26. Mason DA, Moore JD, Green SA, Liggett SB. A gain-of-function polymorphism in a G-protein coupling domain of the human beta1-adrenergic receptor. J Biol Chem. 1999;274:12670-4.

27. Liggett SB, Mialet-Perez J, Thaneemit-Chen S, Weber SA, Greene SM, Hodne D, et al. A polymorphism within a conserved beta(1)adrenergic receptor motif alters cardiac function and betablocker response in human heart failure. Proc Natl Acad Sci U S A. 2006;103:11288-93.

28. Bengtsson K, Melander O, Orho-Melander M, Lindblad U, Ranstam J, Råstam L, et al. Polymorphism in the beta(1)-adrenergic receptor gene and hypertension. Circulation. 2001;104:187-90.

29. Bruck H, Leineweber K, Temme T, Weber M, Heusch G, Philipp $\mathrm{T}$, et al. The Arg $389 \mathrm{Gly}$ beta1-adrenoceptor polymorphism and catecholamine effects on plasma-renin activity. J Am Coll Cardiol. 2005;46:2111-5.

30. Mahanonda N, Bhuripanyo K, Kangkagate C, Wansanit K, Kulchot B, Nademanee $K$, et al. Randomized double-blind, placebo-controlled trial of oral atenolol in patients with unexplained syncope and positive upright tilt table test results. Am Heart J. 1995;130:1250-3.

31. Iskos D, Dutton J, Scheinman MM, Lurie KG. Usefulness of pindolol in neurocardiogenic syncope. Am J Cardiol. 1998;82: 1121-4, A9.

32. Flevari P, Livanis EG, Theodorakis GN, Zarvalis E, Mesiskli T, Kremastinos DT. Vasovagal syncope: a prospective, randomized, crossover evaluation of the effect of propranolol, nadolol and placebo on syncope recurrence and patients' well-being. J Am Coll Cardiol. 2002;40:499-504.

33. Theodorakis GN, Leftheriotis D, Livanis EG, Flevari $P$, Karabela $\mathrm{G}$, Aggelopoulou N, et al. Fluoxetine vs. propranolol in the treatment of vasovagal syncope: a prospective, randomized, placebo-controlled study. Europace. 2006;8:193-8.

34. Dorn GW 2nd, Liggett SB. Mechanisms of pharmacogenomic effects of genetic variation within the cardiac adrenergic network in heart failure. Mol Pharmacol. 2009;76:466-80.

35. Johnson JA, Liggett SB. Cardiovascular pharmacogenomics of adrenergic receptor signaling: clinical implications and future directions. Clin Pharmacol Ther. 2011;89:366-78.

36. Cresci S, Dorn GW 2nd, Jones PG, Beitelshees AL, Li AY, Lenzini PA, et al. Adrenergic-pathway gene variants influence beta-blocker-related outcomes after acute coronary syndrome in a race-specific manner. J Am Coll Cardiol. 2012; 60:898-907.

37. Mialet Perez J, Rathz DA, Petrashevskaya NN, Hahn HS, Wagoner LE, Schwartz A, et al. Beta 1-adrenergic receptor polymorphisms confer differential function and predisposition to heart failure. Nat Med. 2003;9:1300-5.

38. Kokut S, Atay IM, Uz E, Akpinar A, Demirdaş A. The polymorphisms of Ser49Gly and Gly389Arg in Beta-1-adrenergic receptor gene in major depression. Noro Psikiyatr Ars. 2015; 52:124-7.

39. Yilmaz A, Kaya MG, Merdanoglu U, Ergun MA, Cengel A, Menevse $\mathrm{S}$. Association of beta-1 and beta- 2 adrenergic receptor gene polymorphisms with myocardial infarction. J Clin Lab Anal. 2009;23:237-43 